\title{
VOLUNTARY UNILATERAL CONVERGENT STRABISMUS OF EITHER EYE*
}

\author{
BY \\ T. P. AGRAWAL $\dagger$ \\ Department of Ophthalmology, Kasturba Medical College, Manipal, India
}

IT is not uncommon for a person. 'to be able to produce a bilateral convergent strabismus (Duke-Elder, 1949), but voluntary convergent unilateral strabismus is rare; two cases were reported by Zentmayer and Reese (1935) and one by Agrawal (1964). A further case is reported below.

\section{Case Report}

A male Hindu doctor aged 28 years reported on October 10, 1962, with the complaint of difficulty in reading (the letters appearing mixed together after reading for some time) for the past 8 years.

He had had many pairs of spectacles, all for compound hypermetropia, without relief of symptoms. About 6 years ago, he had been advised to do convergence exercises, first looking at a distant object and then looking suddenly at a finger held near the eyes. When he looked at the finger, the distant object appeared double, and he had since started to practise producing diplopia voluntarily.

Examination.-The eyes and their movements and the fundi were normal.

The visual acuity in the right eye was $6 / 6$, with $+0.25 \mathrm{D}$ sph., $+0.75 \mathrm{D}$ cyl., axis $120^{\circ}$ and in the left $6 / 6$, with $+0.25 \mathrm{D}$ sph., $+0.50 \mathrm{D}$ cyl., axis $75^{\circ}$.

The near point of accommodation was $52 \mathrm{~cm}$., the near point of convergence $34 \mathrm{~cm}$., and the interpupillary distance $64 \mathrm{~mm}$.

Maddox Rod Test: Orthophoria.

Maddox Wing Test: Exophoria $10 \triangle$, reduced to $6 \triangle$ immediately.

Prism Vergence Power Test - $4 \Delta$ base up.

$$
\begin{aligned}
& -5 \Delta \text { base in. } \\
& \text { - } 41 \Delta \text { base out. }
\end{aligned}
$$

With voluntary effort, the near point of accommodation and convergence could be brought very close to the eyes and the Maddox rod and Maddox wing tests showed marked esophoria.

He could produce a voluntary convergent strabismus of either eye in all directions of gaze (Fig. $A^{1}$ to $\mathrm{I}^{1}$ and $\mathrm{A}^{2}$ to $\mathrm{I}^{2}$ ). The degree of squint varied with the voluntary effort, the maximum being about $30^{\circ}$. He could also voluntarily converge both eyes at the same time $\left(E^{3}\right)$. While looking at the Snellen chart and making the maximum effort of one eye or both, the pupils were much constricted, the anterior chambers became shallower, the visual acuity was reduced to $2 / 60$ and there was homonymous diplopia for distance. The visual acuity could be improved to $6 / 6$ with $-7 \mathrm{D} \mathrm{sph}$. The fundi could not be seen because of the constriction of the pupillary aperture.

* Received for publication December 7, 1964

$\dagger$ Present address: Department of Ophthalmology, General Hospital, Pondicherry, India. 

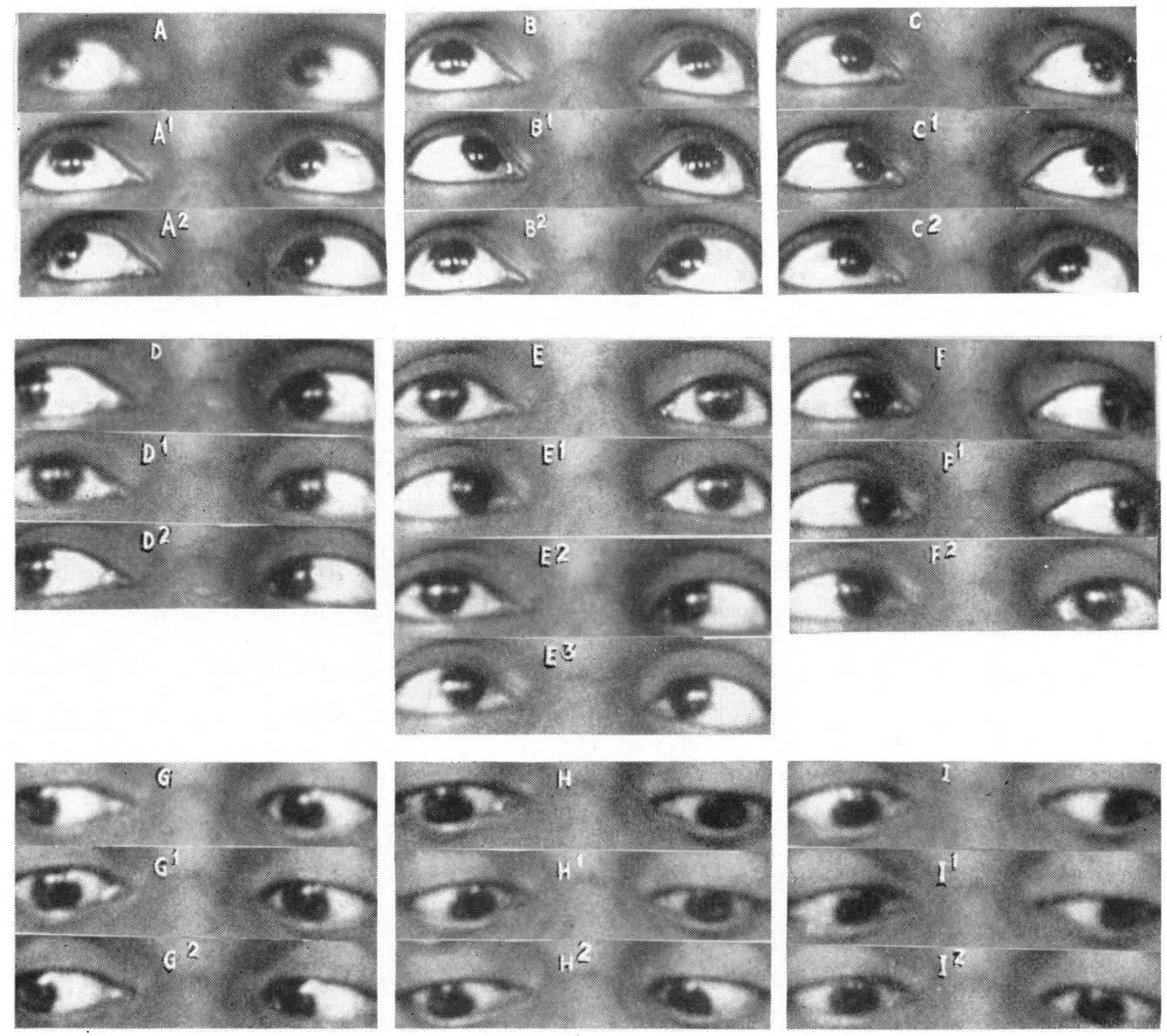

Figure.-Voluntary convergent strabismus.

A to I Maintenance of parallelism of both eyes in all directions of gaze.

$A^{1}$ to $I^{1}$ Right convergent strabismus in all directions of gaze.

$A^{2}$ to $I^{2}$ Left convergent strabismus in all directions of gaze.

$\mathbf{E}^{3} \quad$ Bilateral convergent squint in primary position.

A-Dextro-elevation; B-Sursumversion; C-Laevo-elevation; D-Dextro-version; E-Primary Position; F-Laevo-version; G-Dextro-depression; H-Deorsumversion; I-Laevo-depression.

Since the near point of accommodation convergence of 52 and $34 \mathrm{~cm}$. respectively could be brought very close to the eyes by voluntary effort, the orthophoria for distance and exophoria of $12^{\Delta}$ for near could also be changed to gross esophoria by voluntary effort; the prism vergence test for convergence showed a value of $41 \Delta$ base-out; a psychic factor was the probable cause of the development of voluntary strabismus in this patient.

As opposed to the extreme low and high figures for voluntary convergence of $60^{\circ}$ and $144^{\circ}$ respectively given by Duane (1926), the maximum convergence produced voluntarily by this patient was about $30^{\circ}$. The physiological association of the three synkinetic movements of convergence, accommodation, and pupillary contraction in both eyes was maintained by unilateral voluntary convergence. 


\section{Summary}

A case of voluntary unilateral convergent strabismus of either eye individually associated with diplopia, blurred vision, miosis, and shallow anterior chamber is reported. The patient could also produce bilateral voluntary convergent strabismus.

\section{REFERENCES}

Agrawal, T. P. (1964). Orient. Arch. Ophthal., $2,44$.

DUANE (1926). Quoted by Duke-Elder (1949).

Duke-Elder, S. (1949). "Text-book of Ophthalmology", vol. 4, pp. 3831, 3982. Kimpton, London.

Zentmayer, W., and Reese, W. S. (1935). Arch. Ophthal. (Chicago), 14, 680. 